\title{
Morphometric regressions for the endangered Knysna seahorse, Hippocampus capensis, in the Swartvlei Estuary from mass stranding events
}

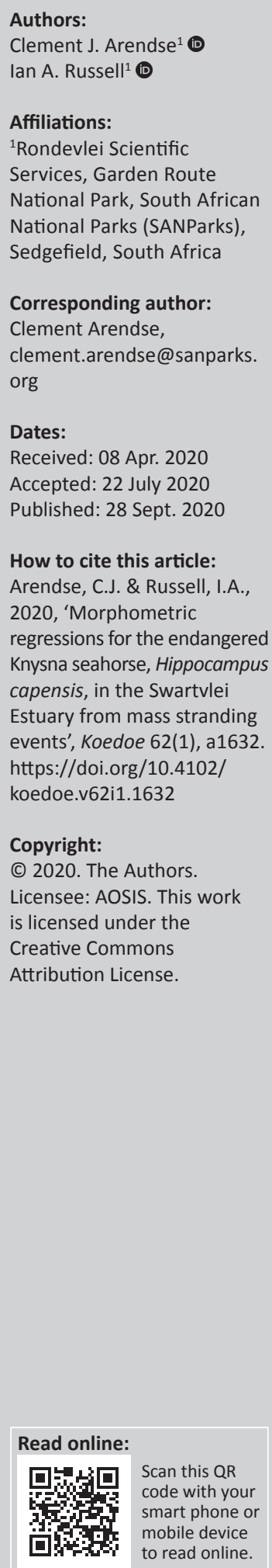

\section{Introduction}

The Knysna seahorse, Hippocampus capensis, is listed as endangered on the IUCN Red List of Threatened Species, with the only known, apparently isolated, populations occurring in the Knysna, Swartvlei and Keurbooms estuaries along the south coast of South Africa. The Swartvlei Estuary population is the most genetically distinct (Mkare et al. 2017). Despite all three known populations occurring within protected areas and there being no commercial or subsistence use of the species, population sizes are still thought to be declining because of habitat degradation across much of its range (Pollom 2017). Environmental management authorities have outlined strategies for the conservation of $H$. capensis, including listing it as a species of special concern in the Estuarine Lower Level Plan of the Garden Route National Park (South African National Parks 2020) and setting management objectives for the Keurbooms population in the Keurbooms-Bitou Estuarine Management Plan (Western Cape Government 2018).

Assessments of population size and habitat use of $H$. capensis have focussed mainly on the relatively larger and more stable population in Knysna Estuary (Bell et al. 2003; Claassens 2016; Claassens \& Hodgson 2018; Teske et al. 2007). The lesser studied Swartvlei Estuary population is subject to large fluctuations in abundance, with past densities ranging from 0.04 individuals per $\mathrm{m}^{2}$ to 0.26 individuals per $\mathrm{m}^{2}$ (Lockyear et al. 2006). The Swartvlei Estuary is the only intermittently open host estuary, with elevated water levels and prolonged flooding of land adjacent to the shores common during closed periods. Periodic mass strandings and associated die-offs of H. capensis have been recorded in Swartvlei Estuary when the estuary is breached (Russell 1994; Skelton 1987), mainly by artificial means to prevent inundation of properties on the estuarine floodplain. The breaching protocol and criteria are contained with the Garden Route National Park Management Plan (SANParks 2020).

South African National Parks (SANParks) as the management authority of Swartvlei Estuary has since 1991 intermittently collected dead H. capensis from the banks of the Swartvlei Estuary after breaching events. This now regular sampling has evolved into a SANParks co-ordinated citizen science programme.

The only known morphometric descriptions of $H$. capensis come from small samples of floodstranded individuals from the Knysna Estuary $(n=57)$ and Swartvlei Estuary $(n=39)$ (Toefy 2000), despite the usefulness of such data in allowing comparison between studies and the conversion of data where different measures of length are used (Lourie 2003).

This article aims to use the seahorse morphometric data collected following two mass stranding events (> 500 individuals) in 1991 and 2017 to provide more robust estimates of the relationship between key morphometric characteristics of $H$. capensis. In addition, data from mass strandings are compared to those collected from seine netting of live individuals in 2019 to determine the feasibility of using these periodic events as a means of assessing population attributes.

\section{Methods}

\section{Sample sites}

Hippocampus capensis were sampled from the Swartvlei Estuary ( $\left.34^{\circ} 01^{\prime} 48.58^{\prime \prime} \mathrm{S}, 22^{\circ} 47^{\prime} 50.66^{\prime \prime} \mathrm{E}\right)$, situated along the south coast of South Africa. 


\section{Collection protocol}

Dead H. capensis were collected after mass stranding events in February 1991 and November 2017. Specimens collected in 1991 were preserved in 10\% neutral freshwater-buffered formalin immediately after collection (Russell 1994), whereas in 2017 dead individuals were frozen immediately after collection. In 2017, samples were collected within 1 day of stranded individuals first being noticed, and for 1 week after estuary breaching. Sampling effort was spread throughout the estuary, although repeat sampling, where sites were searched daily over the sampling period, was undertaken mostly in areas with previous high abundance (Lockyear et al. 2006). Approximately 1000 individuals were recorded, of which half $(52 \%)$ were dead. All live individuals were returned to the water. Retained dead individuals showed various levels of desiccation, likely a result of differences in exposure time because of the intermittent stranding of $H$. capensis over several days following breaching. Samples were pooled for all sites, and all samples were preserved without manipulating (i.e. straightening) body parts.

Live H. capensis were collected in March 2019 using a $10 \mathrm{~m} \times 1.5 \mathrm{~m}$ seine net with a stretched mesh size of $8 \mathrm{~mm}$. Three effective hauls were undertaken in $\leq 1.3 \mathrm{~m}$ water depth in areas of previous high $H$. capensis density, with each haul being approximately $3 \mathrm{~m}$ wide, ranging from $12 \mathrm{~m}$ to $21 \mathrm{~m}$ long, and spaced at least $20 \mathrm{~m}$ apart. Data were pooled for all replicates. Live samples were compared to preserved samples to determine if size classes and sex ratios differed between sampling techniques.

\section{Morphometrics}

Preserved samples were photographed and measured using ImageJ software. Where necessary, individuals were flattened before being photographed to minimise bias in measurements because of body arching (discussed in Sotola et al. 2019).

All individuals were sexed and then measured using the protocol set by Lourie (2003). Head length $(H d L)$, curved trunk length $(\operatorname{Tr} L)$, curved tail length $(\mathrm{TaL})$ and height $(\mathrm{Ht})$ were measured, with standard length $(S L)$ calculated as the sum of the first three measurements. Straight-line $S L\left(S L_{\text {straight }}\right)$ and straight-line $\mathrm{Ht}\left(\mathrm{Ht}_{\text {straight }}\right)$ were also determined for a subsample of individuals whose heads were positioned at a right angle to their trunk. The trunk measurements for the straight-line sizes were measured as straight-line distances from the respective anterior starting points ending at the last trunk ring. Regression equations of size measurements of $H$. capensis included measurement of $H t_{\text {straight }}$ and $H t$ because $H t_{\text {straight }}$ is often the size measurement used when sampling live specimens (Foster \& Vincent 2004; Lourie 2003), likely to avoid handling stress, and $H t$ may be useful if the snout of a dead seahorse is damaged. Live individuals collected in 2019 were sexed and $H t_{\text {straight }}$ was measured before the animals were released at the location of capture.
The effect of preservation techniques on morphometric relationships was investigated by comparing the regression equations between $S L$ and $H d L, T r L, T a L$ and $H t_{\text {straight }}$ of formalin preserved (collected 1991) and frozen (collected 2017) specimens. Preservation of samples in a fixative can cause shrinkage, and different preservation techniques may result in different shrinkage rates of seahorse body parts (Nadeau, Curtis \& Lourie 2009). Also, further shrinkage is known to occur in fish when multiple preservation techniques, in this case freezing or preservation in formalin after desiccation, are applied (Sotola et al. 2019).

\section{Statistical analysis}

Sex ratio bias within the 1991, 2017 and 2019 datasets was tested using an exact binomial test (Crawley 2007; Zar 2010). Sexes were analysed separately because of known sexual dimorphism (Bell et al. 2003).

Normality of $S L$ (between preservation techniques) and $\mathrm{Ht}_{\text {straight }}$ (between alive and preserved specimens) measurements for years and sexes were tested using a Shapiro-Wilk test. Homogeneity of variances was tested using a Fligner-Killeen test before differences in means were tested using either a one-tailed Welch's two-sample $t$-test or a one-tailed Wilcoxon rank-sum test. Differences in mean $\mathrm{Ht}_{\text {straight }}$ between years were tested using a Kruskal-Wallis rank-sum test. Regression equations of $\mathrm{SL}$ and $\mathrm{Ht}_{\text {straight }}$ and their component measurements for years and sexes were produced separately using ordinary least squares regressions and compared to determine if sex and preservation techniques influenced correlation between variables. Regression equations of $S L$ and $H t_{\text {straight }}$, separated by year and sex, were tested using an analysis of covariance (ANCOVA) to determine if regression equations obtained differed significantly (Crawley 2007; Zar 2010).

Data analyses were undertaken using the programming language R (R Core Team 2019).

\section{Results Sex ratios}

Sex ratios were biased towards females in the 1991 sample $(1.025: 1 ; n=170)$ and males in the 2017 and 2019 samples (0.974:1; $n=304$ and $0.814: 1 ; n=78$, respectively), although none differed significantly from the predicted $1: 1$ ratio $(p>0.05)$.

\section{Size class distribution}

Mean length of $H$. capensis collected in 2017 (62 mm - $100 \mathrm{~mm}$ $S L ; n=274$ ) was significantly larger than the mean length of those collected in 1991 (33 mm - $100 \mathrm{~mm} \mathrm{SL;} n=161)$ when sexes were grouped $(W=7800 ; p<0.05)$ as well as for females $(W=1650 ; p<0.05)$ and males $(W=2227 ; p<0.05)$ separately. The majority of individuals collected in 2017 were above the size of sexual maturity ( $\geq 65 \mathrm{~mm} \mathrm{SL}$ [Whitfield 1995]), whereas most individuals collected in 1991 were likely sexually immature (Figure 1a). Mean SL differed significantly 


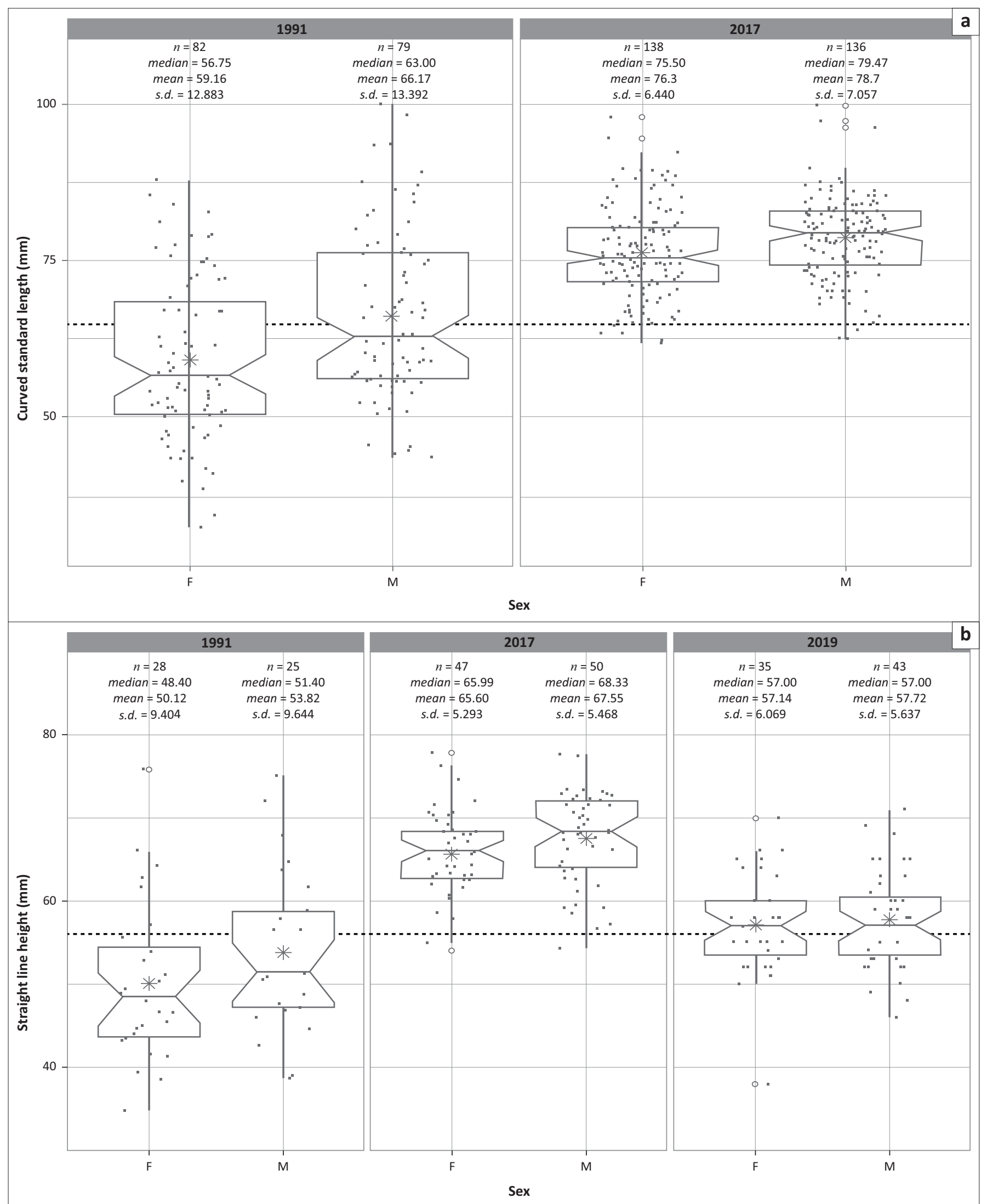

Dotted horizontal lines represent the estimated size at sexual maturity; open circles are outliers; notches are confidence intervals around the median; solid circles are individual observations; and asterisks represent mean values.

The sample size $(n)$, median, mean and standard deviation $(s . d$.) around the mean are provided in the text associated with each plot.

F, Female; M, Male.

FIGURE 1: Box and whisker plots of Hippocampus capensis separated by sex showing the minimum, first quartile, median, third quartile and maximum sizes of (a) SL for preserved (1991 and 2017) samples, and (b) $H t_{\text {straight }}$ for preserved (1991 and 2017) and live samples (2019). 
TABLE 1: Correlation between selected morphometric characteristics of Hippocampus capensis collected in 1991.

\begin{tabular}{|c|c|c|c|c|c|c|c|c|}
\hline$x$-Variable & $y$-Variable & Sex & $n$ & Regression equation & $\varepsilon$ & Intercept SE & Slope SE & Adjusted $R^{2}$ \\
\hline$H t$ & $S L$ & $\mathrm{~F}$ & 81 & $y_{\mathrm{i}}=1.121 x_{\mathrm{i}}-1.205+\hat{\varepsilon}_{\mathrm{i}}$ & $\varepsilon \sim N\left(0,0.988^{2}\right)$ & \pm 0.507 & \pm 0.010 & 0.994 \\
\hline$H t$ & $S L$ & M & 77 & $y_{\mathrm{i}}=1.127 x_{\mathrm{i}}+0.551+\hat{\varepsilon}_{\mathrm{i}}$ & $\varepsilon \sim N\left(0,0.933^{2}\right)$ & \pm 0.529 & \pm 0.009 & 0.995 \\
\hline$H t_{\text {straight }}$ & $S L$ & $\mathrm{~F}$ & 26 & $y_{\mathrm{i}}=1.171 x_{\mathrm{i}}-0.084+\hat{\varepsilon}_{\mathrm{i}}$ & $\varepsilon \sim N\left(0,1.04^{2}\right)$ & \pm 1.094 & \pm 0.021 & 0.991 \\
\hline$H t_{\text {straight }}$ & $S L$ & M & 23 & $y_{\mathrm{i}}=1.204 x_{\mathrm{i}}-1.848+\hat{\varepsilon}_{\mathrm{i}}$ & $\varepsilon \sim N\left(0,1.177^{2}\right)$ & \pm 1.361 & \pm 0.025 & 0.990 \\
\hline$S L_{\text {straight }}$ & $S L$ & $\mathrm{~F}$ & 26 & $y_{\mathrm{i}}=1.019 x_{\mathrm{i}}-0.008+\hat{\varepsilon}_{\mathrm{i}}$ & $\varepsilon \sim N\left(0,0.529^{2}\right)$ & \pm 0.554 & \pm 0.009 & 0.998 \\
\hline$S L_{\text {straight }}$ & $S L$ & M & 23 & $y_{\mathrm{i}}=1.019 x_{\mathrm{i}}+0.217+\hat{\varepsilon}_{\mathrm{i}}$ & $\varepsilon \sim N\left(0,0.498^{2}\right)$ & \pm 0.556 & \pm 0.009 & 0.998 \\
\hline$H d L$ & $S L$ & M & 77 & $y_{\mathrm{i}}=5.945 x_{\mathrm{i}}-3.255+\hat{\varepsilon}_{\mathrm{i}}$ & $\varepsilon \sim N\left(0,4.238^{2}\right)$ & \pm 2.664 & \pm 0.224 & 0.900 \\
\hline $\operatorname{TrL}$ & $S L$ & $\mathrm{~F}$ & 81 & $y_{\mathrm{i}}=3.575 x_{\mathrm{i}}+2.829+\hat{\varepsilon}_{\mathrm{i}}$ & $\varepsilon \sim N\left(0,3.328^{2}\right)$ & \pm 1.713 & \pm 0.106 & 0.933 \\
\hline $\operatorname{TrL}$ & $S L$ & M & 77 & $y_{\mathrm{i}}=3.562 x_{\mathrm{i}}+5.766+\hat{\varepsilon}_{\mathrm{i}}$ & $\varepsilon \sim N\left(0,4.450^{2}\right)$ & \pm 2.459 & \pm 0.142 & 0.900 \\
\hline $\operatorname{Tr} L_{\text {straight }}$ & $S L$ & $\mathrm{~F}$ & 26 & $y_{\mathrm{i}}=3.742 x_{\mathrm{i}}+3.857+\hat{\varepsilon}_{\mathrm{i}}$ & $\varepsilon \sim N\left(0,3.501^{2}\right)$ & \pm 3.597 & \pm 0.241 & 0.903 \\
\hline $\operatorname{Tr} L_{\text {straight }}$ & $S L$ & M & 23 & $y_{\mathrm{i}}=3.407 x_{\mathrm{i}}+13.290+\hat{\varepsilon}_{\mathrm{i}}$ & $\varepsilon \sim N\left(0,5.230^{2}\right)$ & \pm 5.163 & \pm 0.347 & 0.799 \\
\hline TaL & $S L$ & $\mathrm{~F}$ & 81 & $y_{\mathrm{i}}=1.693 x_{\mathrm{i}}+3.950+\hat{\varepsilon}_{\mathrm{i}}$ & $\varepsilon \sim N\left(0,1.931^{2}\right)$ & \pm 0.954 & \pm 0.029 & 0.978 \\
\hline$T a L$ & $S L$ & M & 77 & $y_{\mathrm{i}}=1.632 x_{\mathrm{i}}+4.900+\hat{\varepsilon}_{\mathrm{i}}$ & $\varepsilon \sim N\left(0,2.117^{2}\right)$ & \pm 1.134 & \pm 0.030 & 0.975 \\
\hline$H t_{\text {straight }}$ & $S L_{\text {straight }}$ & $\mathrm{M}$ & 23 & $y_{\mathrm{i}}=1.181 x_{\mathrm{i}}-1.983+\hat{\varepsilon}_{\mathrm{i}}$ & $\varepsilon \sim N\left(0,1.130^{2}\right)$ & \pm 1.307 & \pm 0.024 & 0.990 \\
\hline
\end{tabular}

$S L$, curved standard length; $S L_{\text {straight }}$ straight-line standard length; SE, standard error; $H t$, curved height; $H t_{\text {straight }}$ straight-line height; $H d L$, head length; $T r L$, curved trunk length; $T r L_{\text {straight }}$ straight-line trunk length; TaL, curved tail length; $F$, female; $M$, male.

TABLE 2: Correlation between selected morphometric characteristics of Hippocampus capensis collected in 2017.

\begin{tabular}{|c|c|c|c|c|c|c|c|c|}
\hline$x$-Variable & $y$-Variable & Sex & $n$ & Regression equation & $\varepsilon$ & Intercept SE & Slope SE & Adjusted $R^{2}$ \\
\hline$H t$ & $S L$ & $\mathrm{~F}$ & 126 & $y_{\mathrm{i}}=1.117 x_{\mathrm{i}}+1.994+\hat{\varepsilon}_{\mathrm{i}}$ & $\varepsilon \sim N\left(0,1.139^{2}\right)$ & \pm 1.043 & \pm 0.016 & 0.974 \\
\hline$H t$ & $S L$ & M & 118 & $y_{\mathrm{i}}=1.140-0.003+\hat{\varepsilon}_{\mathrm{i}}$ & $\varepsilon \sim N\left(0,1.311^{2}\right)$ & \pm 1.413 & \pm 0.020 & 0.959 \\
\hline$H t_{\text {straight }}$ & $S L$ & $\mathrm{~F}$ & 35 & $y_{\mathrm{i}}=1.105 x_{\mathrm{i}}+4.346+\hat{\varepsilon}_{\mathrm{i}}$ & $\varepsilon \sim N\left(0,1.456^{2}\right)$ & \pm 2.669 & \pm 0.041 & 0.942 \\
\hline$H t_{\text {straight }}$ & $S L$ & M & 32 & $y_{\mathrm{i}}=1.150 x_{\mathrm{i}}+0.619+\hat{\varepsilon}_{\mathrm{i}}$ & $\varepsilon \sim N\left(0,1.721^{2}\right)$ & \pm 3.047 & \pm 0.045 & 0.930 \\
\hline$S L_{\text {straight }}$ & $S L$ & $\mathrm{~F}$ & 35 & $y_{\mathrm{i}}=0.979 x_{\mathrm{i}}+0.590+\hat{\varepsilon}_{\mathrm{i}}$ & $\varepsilon \sim N\left(0,1.094^{2}\right)$ & \pm 2.083 & \pm 0.027 & 0.967 \\
\hline$S L_{\text {straight }}$ & $S L$ & M & 32 & $y_{\mathrm{i}}=1.015 x_{\mathrm{i}}-2.361+\hat{\varepsilon}_{\mathrm{i}}$ & $\varepsilon \sim N\left(0,1.318^{2}\right)$ & \pm 2.387 & \pm 0.030 & 0.959 \\
\hline$H d L$ & $S L$ & $\mathrm{~F}$ & 138 & $y_{\mathrm{i}}=4.518 x_{\mathrm{i}}+20.552+\hat{\varepsilon}_{\mathrm{i}}$ & $\varepsilon \sim N\left(0,4.605^{2}\right)$ & \pm 4.108 & \pm 0.332 & 0.574 \\
\hline$H d L$ & $S L$ & M & 136 & $y_{\mathrm{i}}=3.396 x_{\mathrm{i}}+37.127+\hat{\varepsilon}_{\mathrm{i}}$ & $\varepsilon \sim N\left(0,4.263^{2}\right)$ & \pm 3.173 & \pm 0.257 & 0.562 \\
\hline $\operatorname{TrL}$ & $S L$ & $\mathrm{~F}$ & 138 & $y_{\mathrm{i}}=2.393 x_{\mathrm{i}}+24.413+\hat{\varepsilon}_{\mathrm{i}}$ & $\varepsilon \sim N\left(0,3.825^{2}\right)$ & \pm 2.872 & \pm 0.132 & 0.706 \\
\hline $\operatorname{TrL}$ & $S L$ & M & 136 & $y_{\mathrm{i}}=2.471 x_{\mathrm{i}}+26.241+\hat{\varepsilon}_{\mathrm{i}}$ & $\varepsilon \sim N\left(0,4.274^{2}\right)$ & \pm 4.012 & \pm 0.188 & 0.560 \\
\hline $\operatorname{Tr} L_{\text {stroight }}$ & $S L$ & $\mathrm{~F}$ & 47 & $y_{\mathrm{i}}=1.905 x_{\mathrm{i}}+39.138+\hat{\varepsilon}_{\mathrm{i}}$ & $\varepsilon \sim N\left(0,4.310^{2}\right)$ & \pm 5.665 & \pm 1.905 & 0.488 \\
\hline $\operatorname{Tr} L_{\text {straight }}$ & $S L$ & $\mathrm{M}$ & 50 & $y_{\mathrm{i}}=2.401 x_{\mathrm{i}}+31.646+\hat{\varepsilon}_{\mathrm{i}}$ & $\varepsilon \sim N\left(0,4.512^{2}\right)$ & \pm 6.373 & \pm 0.326 & 0.521 \\
\hline$T a L$ & $S L$ & $\mathrm{~F}$ & 138 & $y_{\mathrm{i}}=1.531 x_{\mathrm{i}}+11.549+\hat{\varepsilon}_{\mathrm{i}}$ & $\varepsilon \sim N\left(0,2.430^{2}\right)$ & \pm 2.038 & \pm 0.048 & 0.882 \\
\hline$T a L$ & $S L$ & M & 136 & $y_{\mathrm{i}}=1.455 x_{\mathrm{i}}+12.908+\hat{\varepsilon}_{\mathrm{i}}$ & $\varepsilon \sim N\left(0,2.226^{2}\right)$ & \pm 2.094 & \pm 0.046 & 0.881 \\
\hline$H t_{\text {straight }}$ & $S L_{\text {straight }}$ & M & 50 & $y_{\mathrm{i}}=1.134 x_{\mathrm{i}}+2.930+\hat{\varepsilon}_{\mathrm{i}}$ & $\varepsilon \sim N\left(0,1.087^{2}\right)$ & \pm 1.925 & \pm 0.028 & 0.970 \\
\hline
\end{tabular}

$S L$, curved standard length; $S L_{\text {straight }}$ straight-line standard length; SE, standard error; $H t$, curved height; $H t_{\text {straight }}$, straight-line height; $H d L$, head length; $T r L$, curved trunk length; $T r L_{\text {straight }}$ straight-line trunk length; TaL, curved tail length; $F$, female; M, male.

between sexes in both $1991(W=2255 ; p<0.05)$ and 2017 $(t=-2.989 ; p<0.05)$, with the mean size of males being larger than that of females in both years.

Measurements of $H t_{\text {straight }}$ from live $H$. capensis collected in 2019 were normally distributed for both females $(W=0.946$; $p>0.05)$ and males $(W=0.984 ; p>0.05)$. Mean $H t_{\text {straight }}$ did not differ significantly between sexes $(t=-0.432 ; p>0.05)$. The 2019 size range $\left(38 \mathrm{~mm}-71 \mathrm{~mm} \mathrm{H} t_{\text {straight }} ; n=78\right)$ was similar to those collected in both 1991 (35 mm - $76 \mathrm{~mm} \mathrm{H} t_{\text {straight }}$; $n=53$ ) and 2017 (54 $\left.\mathrm{mm}-77 \mathrm{~mm} \mathrm{H} t_{\text {straight }} n=97\right)$, though mean sizes differed significantly for both females (chi-squared $=51.875 ; p<0.05$ ) and males between years (chi-squared $=52.689 ; p<0.05)($ Figure $1 b)$.

\section{Morphometric regressions}

The fit of regression models between SL and HdL, TrL and TaL was better for the 1991 samples compared to those collected in 2017, as evidenced by the high $R^{2}$ values in the former
(Tables 1 and 2). Test statistics for the regressions between $S L$ and $H d L, T r L, T a L$ and $H t_{\text {straight }}$ are presented in Table 3. HdL, $\operatorname{Tr} L$ and $T a L$ were significantly correlated to $S L$ for both sexes when years were analysed separately, whilst sex effected all regressions except $H d L$ in 1991. Interaction did not significantly effect the fit of the models in either year $(p>0.05)$ and the slope of the models did not differ significantly between sexes $(p>0.05)$, with the exception of HdL in 2017. When differences between years were calculated separately for sexes, interaction effects were evident for the female datasets for TrL and TaL and male datasets for $H d L$ and $\operatorname{Tr} L$ $(p>0.05)$ but not the female dataset for $H d L$ or the male dataset for TaL. Year significantly effected all regressions except the male dataset for $\operatorname{Tr} L$. Slopes differed between years for all variables for both sexes. Preservation technique, therefore, influenced $\operatorname{Tr} L$ for both sexes, whereas $H d L$ only differed between males and $T a L$ between females. When years were analysed individually, $\mathrm{Ht}_{\text {straight }}$ significantly effected SL in 1991 and $2017(p<0.05)$, but sex effected the regressions only in $2017(p<0.05)$. No interaction effects were 
TABLE 3: Test statistics of regression models of standard length with head length, curved trunk length and curved tail length, showing interaction between the measured variables and sexes and years, respectively.

\begin{tabular}{|c|c|c|c|c|}
\hline Model & $x$-Variable & Grouping variable & Interaction & Slope \\
\hline$S L_{1991} \sim H d L_{1991} * \operatorname{Sex}$ & 325.470 & 0.959 & 0.0315 & -1.365 \\
\hline $\mathrm{SL}_{2017} \sim H d L_{2017} * \mathrm{Sex}$ & 88.387 & 9.828 & 0.6315 & 2.690 \\
\hline $\mathrm{SL}_{1991}^{\sim} \operatorname{TrL}_{1991} * \mathrm{Sex}$ & 397.410 & 9.464 & 0.1775 & 0.071 \\
\hline $\mathrm{SL}_{2017}^{\sim} \operatorname{TrL}_{2017} * \mathrm{Sex}$ & 111.676 & 9.141 & 0.6889 & -0.343 \\
\hline $\mathrm{SL}_{1991} \sim \mathrm{TaL}_{1991}{ }^{*} \mathrm{Sex}$ & 1317.634 & 8.341 & 0.9709 & 1.469 \\
\hline $\mathrm{SL}_{2017} \sim \mathrm{TaL}_{2017} * \mathrm{Sex}$ & 513.837 & 9.436 & 0.0133 & 1.145 \\
\hline$S L_{1991} \sim H t_{\text {straight(1991) }} *$ Sex & 6319.06 & 0.827 & 1.133 & -1.008 \\
\hline$S L_{2017} \sim H t_{\text {straight(2017) }} *$ Sex & 3638.625 & 8.320 & 0.0026 & -0.734 \\
\hline$S L_{F} \sim H d L_{F}^{*}$ Year & 541.182 & 106.962 & 2.7792 & 2.508 \\
\hline$S L_{M} \sim H d L_{M}{ }^{*}$ Year & 284.61 & 142.26 & 7.1196 & 7.462 \\
\hline$S L_{F} \sim \operatorname{Tr} L_{F}^{*}$ Year & 727.50 & 11.15 & 19.669 & 6.898 \\
\hline$S L_{M} \sim \operatorname{Tr} L_{M}{ }^{*}$ Year & 495.947 & 4.792 & 6.8645 & 4.625 \\
\hline$S L_{F} \sim T a L_{F}^{*}$ Year & 1905.621 & 18.522 & 4.4768 & 2.899 \\
\hline $\mathrm{SL}_{M} \sim T a L_{M}{ }^{*}$ Year & 1910.512 & 29.439 & 3.0692 & 3.243 \\
\hline $\mathrm{S} L_{F} \sim H t_{\text {straight( F) }} *$ Year & 15057.984 & 76.374 & 0.3122 & 1.428 \\
\hline$S L_{M} \sim H t_{\text {straight(M) }}$ *Year & 8521.251 & 29.887 & 1.5973 & 1.016 \\
\hline
\end{tabular}

Note: Values in bold are significant $(p<0.05)$.

$S L$, curved standard length; $H t_{\text {stroght }}$ straight-line height; $H d L$, head length; $T r L$, curved trunk

evident in either year $(p>0.05)$. When sexes were analysed separately, $H t_{\text {straight }}$ and year significantly influenced the regressions for both sexes, with no interaction effects evident for females or males $(p>0.05)$. The linear regression for males collected in 1991 (Table 1) was used to calculate $H t_{\text {straight }}$ at sexual maturity (56 mm) (Figure 1b).

\section{Discussion}

The 1991 and 2017 datasets provided reliable correlations between the morphometric variables measured for the different preservation techniques. Both preservation techniques used in this study are known to result in significant shrinkage of fish bodies (Berbel-Filho, Jacobina \& Martinez 2013; Buchheister \& Wilson 2005; Nadeau et al. 2009) with the preservation of samples in formalin and ethanol resulting in ongoing shrinkage of body parts (Martinez, Berbel-Filho \& Jacobina 2013; Sotola et al. 2019). To compound the complexity of using preserved specimens in morphometric investigations, shrinkage in fish may not be uniform across body parts and differences can even be observed at an individual level (Sotola et al. 2019). This effect was noted in this study with the regressions of $S L$ with $H d L, T r L$ and TaL of $H$. capensis collected in 2017, showing greater variation than those collected in 1991. Although the individuals collected in 2017 were frozen before processing, they showed differing levels of desiccation when collected. This, coupled with an extended, staggered collection period for the stranded seahorses, and the relatively shorter period between preservation and processing of samples compared to the 1991 dataset, could have contributed to the larger variation in the body length ratios. The greater correlation between morphometric measurements of $S L$ and $H d L, T r L$ and TaL in 1991 was therefore likely because of more even shrinkage resulting from prolonged exposure of the samples to the fixative. This result, together with the differences in slopes between the 2 years, suggests that different regression equations are needed for each preservation type and that comparisons between samples preserved in different fixatives may require correction factors to be calculated by measuring samples before and at several periods after preservation. In addition, using regression equations obtained from preserved specimens to describe morphometric relationships of live specimens is not recommended.

The mean length $\left(\mathrm{Ht}_{\text {straight }}\right)$ of $\mathrm{H}$. capensis differed significantly between 1991, 2017 and 2019 for both sexes. Differences could relate to the timing of the breaching events, with both the 1991 and 2019 samples collected towards the end of the breeding period for $H$. capensis (austral summer - Whitfield [1995]), whereas the 2017 samples were collected at the start of the breeding period, potentially explaining the lower proportion of smaller individuals in that year. The duration of preservation of specimens could also have contributed to differences in mean length, with specimens collected in 1991 being subjected to longer exposure to a fixative likely having shrunk to a greater degree.

Although differences in the size data existed, the slopes of the $S L$ versus $H t_{\text {straight }}$ regressions for 1991 and 2017 did not differ significantly from one another, indicating that the relationship between $S L$ and $H t_{\text {straight }}$ remains relatively constant regardless of preservation technique used. This was, however, not the case for the relationship between $S L$ and $H d L, T r L$ and $T a L$, where preservation technique, as well as sex, influenced the slopes of the regressions. As various length measurements are often used for measuring seahorses, standardisation of seahorse measurements is difficult (Foster \& Vincent 2004). The morphometric regressions presented in Tables 1 and 2 can assist in comparing the results of previous studies where different measurements and preservation methods were used.

Equal sex ratios observed in 1991 and 2017 were similar to those found in in situ studies of natural populations (Lockyear et al. 2006) and in 2019, suggesting that stranding affected both sexes equally. The use of stranding data for H. capensis in the Swartvlei Estuary could be a novel way of post hoc determination of population attributes, as data collected from these events are comparable to those collected from the study of in situ populations. The effects of preservation on morphometric variables also need additional consideration, and shrinkage correction equations should be developed for different preservation methods and durations.

\section{Acknowledgements}

The authors would like to thank the citizen scientists, SANParks staff and honorary rangers for their assistance with data collection. They would also like to thank DrMohlamatsane Mokhatla for his help with the statistical programme R.

\section{Competing interests}

The authors have declared that no competing interest exists. 


\section{Authors' contributions}

C.J.A. and I.A.R. conceptualised the study, conducted fieldwork and contributed to writing the article. C.J.A. performed all laboratory and statistical analysis.

\section{Ethical consideration}

This study fully meets the ethical standards for handling of Hippocampus capensis as set out by the SANParks Animal Use and Care Committee (004/17).

\section{Funding information}

This research received no specific grant from any funding agency in the public, commercial or not-for-profit sectors.

\section{Data availability statement}

Data can be requested via the SANParks data repository (http:/ /dataknp.sanparks.org/sanparks/). Data use limitations may apply.

\section{Disclaimer}

The views and opinions expressed in this article are those of the authors and do not necessarily reflect the official policy or position of any affiliated agency of the authors.

\section{References}

Bell, E.M., Lockyear, J.F., McPherson, J.M., Marsden, A.D. \& Vincent, A.C.J., 2003, 'First field studies of an endangered South African seahorse, Hippocampus capensis' Environmental Biology of Fishes 67(1), 35-46. https://doi.org/10.1023/A:102444 0717162

Berbel-Filho, W.M., Jacobina, U.P. \& Martinez, P.A., 2013, 'Preservation effects in geometric morphometric approaches: Freezing and alcohol in a freshwater fish', Ichthyological Research 60(3), 268-271. https://doi.org/10.1007/s10228-0130339-x

Buchheister, A. \& Wilson, M.T., 2005, 'Shrinkage correction and length conversion equations for Theragra chalcogramma, Mallotus villosus and Thaleichthys pacificus' Journal of Fish Biology 67(2), 541-548. https://doi.org/10.1111/j.0022-1112. 2005.00741.x

Claassens, L., 2016, 'An artificial water body provides habitat for an endangered estuarine seahorse species', Estuarine, Coastal and Shelf Science 180, 1-10. https://doi.org/10.1016/j.ecss.2016.06.011
Claassens, L. \& Hodgson, A.N., 2018, 'Gaining insights into in situ behaviour of an endangered seahorse using action cameras', Journal of Zoology 304(2), 98-108. https://doi.org/10.1111/jzo.12509

Crawley, M.J., 2007, The R Book, John Wiley \& Sons, Ltd, The Atrium, Southern Gate, Chichester, West Sussex, England.

Foster, S.J. \& Vincent, A.C.J., 2004, 'Life history and ecology of seahorses: Implications for conservation and management', Journal of Fish Biology 65(1), 1-61. https:// doi.org/10.1111/j.0022-1112.2004.00429.x

Lockyear, J.F., Hecht, T., Kaiser, H. \& Teske, P.R., 2006, 'The distribution and abundance of the endangered Knysna seahorse Hippocampus capensis (Pisces: Syngnathidae) in South African estuaries', African Journal of Aquatic Science 31(2), 275-283. https://doi.org/10.2989/16085910609503897

Lourie, S., 2003, Measuring seahorses, Project seahorse technical report no. 4, version 1.0, p. 15, Project seahorse, Fisheries Centre, University of British Columbia.

Martinez, P.A., Berbel-Filho, W.M. \& Jacobina, U.P., 2013, 'Is formalin fixation and ethanol preservation able to influence in geometric morphometric analysis? Fishes as a case study', Zoomorphology 132(1), 87-93. https://doi.org/10.1007/ s00435-012-0176-x

Mkare, T.K., Jansen van Vuuren, B. \& Teske, P.R., 2017, 'Conservation implications of significant population differentiation in an endangered estuarine seahorse' Biodiversity and Conservation 26(6), 1275-1293. https://doi.org/10.1007/ s10531-017-1300-5

Nadeau, J.L., Curtis, J.M.R. \& Lourie, S.A., 2009, 'Preservation causes shrinkage in seahorses: Implications for biological studies and for managing sustainable trade with minimum size', Aquatic Conservation: Marine and Freshwater Ecosystems 19(4), 428-438. https://doi.org/10.1002/aqc.1002

Pollom, R.A., 2017, 'Hippocampus capensis', The IUCN Red list of threatened species 2017, e.T10056A54903534.

$\mathrm{R}$ Core Team, 2019, R: A language and environment for statistical computing, $\mathrm{R}$ Foundation for Statistical Computing, Vienna, viewed 07 October 2019, from https:// www.R-project.org/.

Russell, I.A., 1994, 'Mass mortality of marine and estuarine fish in the Swartvlei and Wilderness lake systems, Southern Cape', Southern African Journal of Aquatic Sciences 20(1-2), 93-96. https://doi.org/10.1080/10183469.1994.9631353

Skelton, P.H., 1987, South African Red Data Book - Fishes, Pretoria, South Africa.

Sotola, V.A., Craig, C.A., Pfaff, P.J., Maikoetter, J.D., Martin, N.H. \& Bonner, T.H., 2019, 'Effect of preservation on fish morphology over time: Implications for morphological studies', PLoS One 14(3), e0213915. https://doi.org/10.1371/ journal.pone.0213915

South African National Parks, 2020, Garden Route National Park Management Plan, p. 222, Groenkloof, South Africa.

Teske, P.R., Lockyear, J.F., Hecht, T. \& Kaiser, H., 2007, 'Does the endangered Knysna seahorse, Hippocampus capensis, have a preference for aquatic vegetation type, cover or height?', African Zoology 42(1), 23-30. https://doi.org/10.3377/15627020(2007)42[23:DTEKSH]2.0.CO;2

Toefy, Z., 2000, 'A preliminary examination of the morphological and genetic structure within populations of the Knysna seahorse Hippocampus capensis (Pisces: Syngnathidae) from two South African estuaries', M.Sc dissertation, University of the Western Cape, Bellville, South Africa, p. 83.

Western Cape Government, 2018, Keurbooms-Bitou Estuarine Management Plan, Cape Town, South Africa, p. 139.

Whitfield, A.K., 1995, 'Threatened fishes of the world: Hippocampus capensis Boulenger, 1900 , Environmental Biology of Fishes 44(2), 362. https://doi.org/10.1007/ BF00008251

Zar, J.H., 2010, Biostatistical analysis, 5th edn., Prentice Hall, Inc, Upper Saddle River, New Jersey. 